\title{
MEMBANGUN SISTEM INFORMASI PARIWISATA BERBASIS WEB PADA DINAS KEBUDAYAAN DAN PARIWISATA KABUPATEN TULANG BAWANG
}

\author{
Merri Parida', Rustam $^{2,}$ Yogi Kurniawan ${ }^{3}$ \\ Program Studi Sistem Informasi ${ }^{\mathbf{1 2 3}}$ \\ STMIK DIAN CIPTA CENDIKIA KOTABUMI \\ Jl.Negara No. 03 Candimas Kotabumi- Lampung Utara \\ Email: merriparida27@gmail.com, rustam@dcc.ac.id,yogi@gmail.com
}

\begin{abstract}
ABSTRAK
Tulang bawang merupakan salah satu daerah yang memiliki tujuan wisata di Lampung, kategori wisata yang menjadi pilihan yaitu wisata alam, wisata budaya, wisata sejarah, dan lain-lain. Tujuan dibuatnya sistem informasi ini adalah untuk sarana promosi wisata agar lebih dikenal oleh masyarakat luas.

Metode perancangan sistem yang digunakan untuk mengidentifikasikan komponenkomponen perancangan sistem informasi meliputi use case diagram, diagram activity, sequence diagram, class diagram, rancangan masukan dan keluaran, serta struktur menu aplikasi. Untuk pembuatan sistem informasi ini menggunakan software notepad dengan bahasa pemrograman PHP dan database MySQL.

Dengan adanya sistem informasi ini, diharapkan dapat mempermudah calon wisatawan dalam mendapatkan informasi mengenai obyek wisata yang akan dikunjungi.
\end{abstract}

Kata kunci : Sistem Informasi, Pariwisata, Tulang Bawang.

\begin{abstract}
Onion is one of the areas that has a tourist destination in Lampung, the category of tourism that became the choice of nature tourism, cultural tourism, historical tours, and others. The purpose of making this information system is to promote tourism facilities tobe better known to the public.

System design methods used to identify components of information system design include use case diagrams, activity diagrams, sequence diagrams, class diagrams, input and output design, and application menu structure. For making this information system using notepad software with PHP programming language and MYSQL database.

With the existence of this information system, is expected to facilitate the prospective tourists in getting information about the tourist attraction to be visited.
\end{abstract}

Keywords: Information System, Tourism, Bone Onion. 


\section{JURnal InformASI dan KomPUTer \\ Volume 6 Nomor 12018 \\ P-ISSN 2337-8344}

\section{PENDAHULUAN \\ 1.1 Latar Belakang}

Pada era globalisasi perkembangan ilmu pengetahuan dan teknologi di indonesia dewasa ini sudah semakin pesat dan membawa perubahan yang sangat besar karena dengan teknologi tersebut informasi dapat dengan cepat, akurat, dan tidak terbatas oleh waktu dan tempat.

Salah satu sektor yang berkembang dalam perkembangan teknologi adalah dibidang pariwisata, yang memberikan andil untuk mendistribusikan informasi mengenai obyek-obyek wisata yang lebih interaktif khususnya melalui teknologi internet, yang berfungsi sebagai fasilitas yang memudahkan dalam penyampaian informasi bagi masyarakat.

Kabupaten Tulang Bawang memiliki potensial pariwisata yang sangat menarik untuk ditelusuri. Keindahan alam dan obyek wisata yang khas menjadikannya sebagai salah satu tujuan wisata yang memiliki daya tarik tersendiri, namun sayangnya saat ini tempat-tempat pariwisata yang ada di kabupaten Tulang Bawang masih belum terpublikasi karena ada beberapa tempat yang letaknya berada jauh didaerah pelosok sehingga penyampaian informasi masih sangat terbatas.Sistem informasi pariwisata daerah Kabupaten Tulang Bawang berbasis web sangat diperlukan sebagai sarana penyampaian informasi kepada masyarakat yang ingin mengetahui daerah-daerah pariwisata yang ada di kabupaten Tulang Bawang.

Sistem informasi ini juga merupakan sebagai sarana promosi, dimana salah satu media perantaranya adalah komputer atau HP (handphone).Diperlukan suatu sistem informasi pariwisata daerah Kabupaten
Tulang Bawang berbasis web untuk menarik wisatawan lokal atau asing untuk berwisata ke kabupaten Tulang Bawang.

Semakin banyak wisatawan berkunjung maka pendapatan daerah dan masyarakat sekitarnya akan mengalami peningkatan. Selain itu dengan adanya sistem informasi pariwisata berbasis web maka obyek-obyek wisata didaerah kabupaten Tulang Bawang akan lebih dikenal oleh masyarakat luar serta memotivasi bagi pemerintah untuk lebih memperhatikan pengelolaan pada tempat-tempat pariwasata tersebut.

\subsection{Identifikasi Masalah}

Berdasarkan latar belakang masalah diatas, maka masalah yang ada dalam penelitian ini antara lain :

1. Lokasi wisata yang kebanyakan berada dipelosok daerah yang kurang diketahui masyarakat.

2. Tempat-tempat wisata yang ada di kabupaten Tulang Bawang masih banyak yangbelum terekspos masyarakat luar.

3. Informasi yang tidak akurat mengenai pariwisata yang ada dikabupaten tulang bawang.

\subsection{Batasan Masalah}

Sesuai dengan identifikasi masalah diatas, dalam penelitian ini penulis perlu membatasi masalah agar tidak menyimpang dari tujuan semula, yaitu :

1. Sistem informasi yang dibangun hanya akan mengolah informasi pariwisata yang ada pada kabupaten Tulang Bawang.

2. Sistem informasi akan menginput dan menampilkan mengenai obyek wisata yang ada di kabupaten Tulang Bawang.

3. Konten wisata yang tersaji pada sistem ini meliputi konten wisata 
alam, sejarah, budaya, dan agro industri.

\subsection{Rumusan Masalah}

Berdasarkan latar belakang masalah yang telah diuraikan diatas, maka dapat dituliskan rumusan masalah dalam proposal ini adalah :

1. Bagaimana merancang sistem informasi kebudayaan dan pariwisata pada kabupaten Tulang Bawang berbasis web ?

2. Bagaimana membangun web yang bisa memberi informasi tentangtempat wisata yang ada di kabupaten Tulang Bawang?

3. Bagaimana sistem informasi ini dapat memberikan rekomendasi wisata bagi wisatawan?

4. Bagaimana sistem ini dapat digunakan untuk entry, edit, dan hapus data-data wisata dan infrastruktur pendukungnya ?

\subsection{Tujuan Penelitian}

Tujuan dalam proposal penelitian ini adalah :

1. Mampu mengembangkan keterampilan dan menerapkan ilmu pengetahuan secara komputerisasi yang didapat di bangku perkuliahan.

2. Merancang sistem informasi pariwisata di kabupaten Tulang Bawang dengan teknologi internet dan bersifat web dinamis.

3. Membantu meningkatkan efektifitas dan efisienkinerja dalam mengumpulkan dan menganalisa data untuk menyelesaikan suatu permasalahan.

4. Untuk memberikan informasi dan mempermudah merekomendasikan tempat wisata kepada wisatawan. $\mathrm{Bab}$ ini berisi kesimpulan yang dibuat penulis dari semua yang telah penulis dari awal perancangan, proses, sampai hasil keluaran berupa website. Dan saran dari penulis untuk organisasi dan untuk kampus itu sendiri.

\section{METODOLOGI PENELITIAN}

\subsection{Jenis Penelitian}

Jenis penelitian yang di pilih peneliti adalah penelitian kualitatif, yaitu serangkaian kegiatan atau proses untuk mengungkapkan proses-proses informasi dalam membangun sistem yang digunakan sebagai dasar dalam perancangan sistem informasi dengan menerapkan tahap-tahap yang ada dalam metode pengembangan sistem, yaitu : planning, analisis, design, pengkodean / implementasi, uji coba, dan perawatan sistem. Peneliti melakukan penelitian ini menggunakan metode wawancara dan observasi. Melalui metode ini, peneliti akan menganalisis data yang didapatkan dari lapangan dengan detail. Obyek dari penelitian ini adalah sistem yang akan dibangun sedangkan subjeknya adalah masyarakat tulang bawang.

\subsection{Populasi}

Populasi penelitian ini yaitu semua wisatawan yang mengunjungi pariwisata yang ada dikabupaten tulang bawang periode lima (5) bulan terakhir yang berjumlah 650 orang.

\subsection{Sampel}

Sampel sebagian dari jumlah dan karakteristik yang dimiliki populasi. Apabila kurang dari 100 lebih baik diambil semua sehinga penelitiannya merupakan penelitian populasi. Jika jumlah subjeknya besar dapat diambil antara $100-15 \%$ atau $20-25 \%$ atau lebih tergantung sedikit banyaknya dari kemampuan peneliti dilihat dari waktu, tenaga, dan biaya (Ari Kunto, 2011). 
Dikarenakan jumlah populasi lebih dari 100 maka peneliti menetapkan sampel penelitian sebanyak $25 \%$ dari jumlah populasi. Jadi sampel penelitian ini $25 \%$ x $650=162,5$ dibulatkan menjadi 163 orang.

\subsection{Metode Pengembangan Sistem \\ Penulis menggunakan metode} Prototyping dalam pengembangan sistem ini, adapun tahap-tahap dalam metode Prototyping antara lain :

\section{Tahap Perencanaan ( Planning )}

Pada tahap perencanaan sistem hal utama yang sangat ditekankan yaitu pengumpulan kebutuhan tingkat sistem dengan cara membuat konsep dari sistem yang akan dibangun. Selain itu, padatahap ini interface juga direncanakan yang nantinya akan menghubungkannya dengan brainware. Hasil dari tahap ini adalah spesifikasi dari sistem yang akan dibangun. Pada tahap ini juga penulis mengidentifikasi kebutuhan user dan sistem.

\section{Tahap Analisis Sistem}

Penguraian dari suatu sistem informasi yang utuh kedalam bagian-bagian komponennya dengan maksud untuk mengidentifikasi dan mengevaluasi permasalaha-permasalahan, kesempatankesempaatan, hambatan-hambatan yang terjadi dan kebutuhan-kebutuhan yang diharapkan sehingga dapat diusulkan perbaikan-perbaikannya. Penulis mengggunakan use case diagram untuk mengusulkan fungsi-fungsi dari sistem.

\section{Tahap Design Sistem}

sistem, tahap selanjutnya adalah desain sistem yang bertujuan menggambarkan bagaimana suatu sistem dibentuk.
Desain sistem dilakukan dengan pendekatan terstruktur ( procedure).

\section{Tahap Pengkodean / Implementasi}

Untuk menjalankan sistem informasi pariwisata yang dibangun harus terintegrasi dengan database agar semua sistem yang telah dibuat dapat berjalan dengan sistematis dan dinamis. Database merupakan kumpulan dari data yang saling berhubungan satu sama lain. Hubungan setiap tabel memiliki relationship data yang dihasilkan mengikuti konsep normalisasi database.

Database yang digunakan dalam pembuatan sistem informasi ini adalah $M y S Q L$, dengan nama databasenya " db_pariwisata". Berikut ini perancangan tabel-tabel yang digunakan beserta fieldfield yang terdapat pada masing- masing tabel.

\section{Uji Coba Sistem ( Testing )}

Ada beberapa jenis uji coba perangkat lunak atau sistem yang dilakukan, antara lain :

1. Developmental, yaitu menguji kebenaran modul-modul dalam bentuk individual dan terintegrasi yang dilakukan oleh programmer.

2. Alpha, menguji sistem secara keseluruhan apakah sudah sesuai dengan kebutuhan atau tidak.

3. Beta, yaitu uji coba kemampuan sistem dalam ruang lingkup pengguna, yang menggunakan data aktual.

\section{Perawatan Sistem}

Proses dimana dilakukan pengembangan terhadap sistem yang sedang berjalan. Berikut ini beberapa ini beberapa bentuk pemeliharaan sistem, antara lain :

1. Korektif, yaitu membuat perubahan pada sistem informasi untuk memperbaiki kesalahan yang terjadi 
pada saat desain, coding, atau implementasi.

2. Adaptif, adalah pengubahan sistem untuk mengembangkan fungsionalitas agar dapat mengakomodasi perubahan kebutuhan bisnis atau untuk migrasi ke lingkungan yang berbeda.

3. Perfektif, yaitu pengembangan untuk meningkatkan kegunaan antar muka atau penambahan fitur sistem yang sebenarnya tidak terlalu diperlukan.

4. Preventif atau pencegahan, adalah pengubahan sistem untuk memperkecil peluang terjadinya kesalahan.

\section{HASIL DAN PEMBAHASAN 3.1 HASIL DAN PEMBAHASAN PROGRAM}

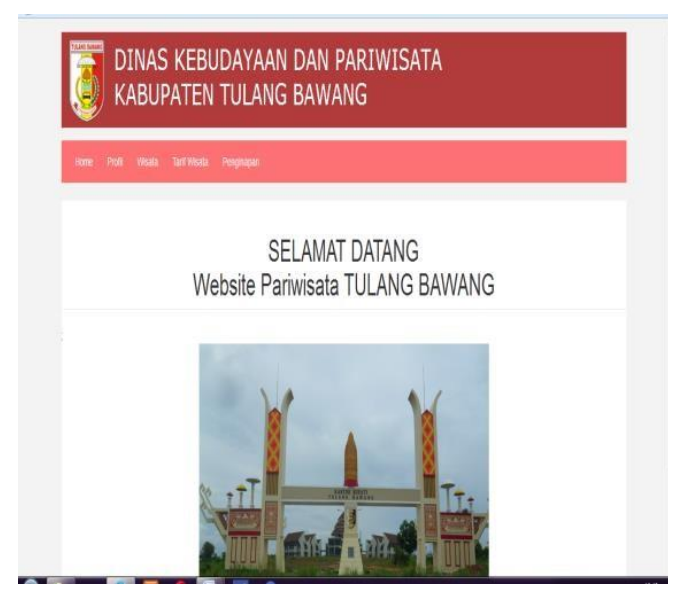

\section{Tampilan Menu Home}

Gambar 1 Tampilan Home

Keterangan : Menu Utama Berisi Menu Wisata, Menu Profil Dinas, Menu Tarif Wisata, Dan Menu Penginapan.

\section{Tampilan Menu Profil Dinas}

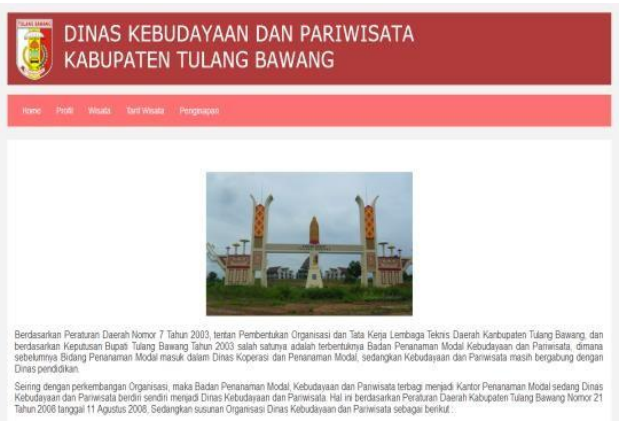

Gambar 2 Tampilan Menu Profil Dinas

Keterangan : Menu profil dinas berisi sejarah, susunan organisasi, dan namanama kepala dinas yang pernah menjabat.

\section{Tampilan Menu Wisata}

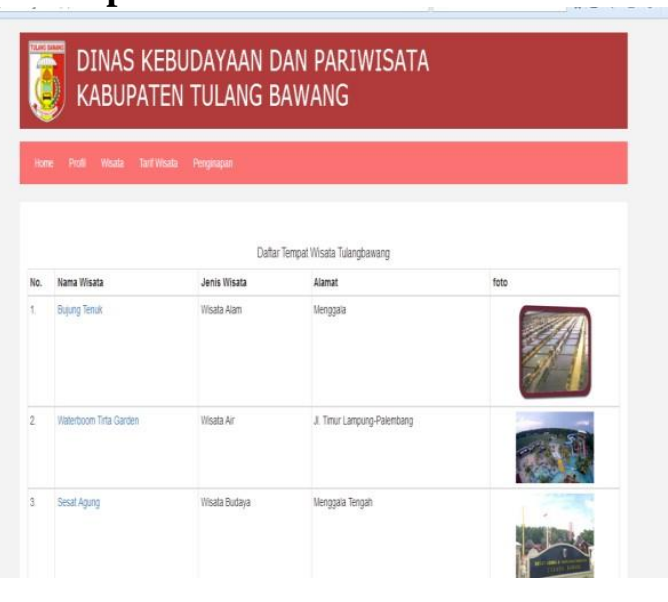

Gambar 3 Tampilan Menu Wisata

Keterangan : Menu wisata berisi Namanama Wisata, Jenis Wisata, Alamat, dan Foto tempat wisata tersebut. Untuk melihat depenelitian salah satu tempat wisata di klik 2 kali pada nama wisata tersebut. 


\section{JURnal InformASI dan KomPUTer \\ Volume 6 Nomor 1 2018}

\section{Tampilan Menu Tarif Wisata}

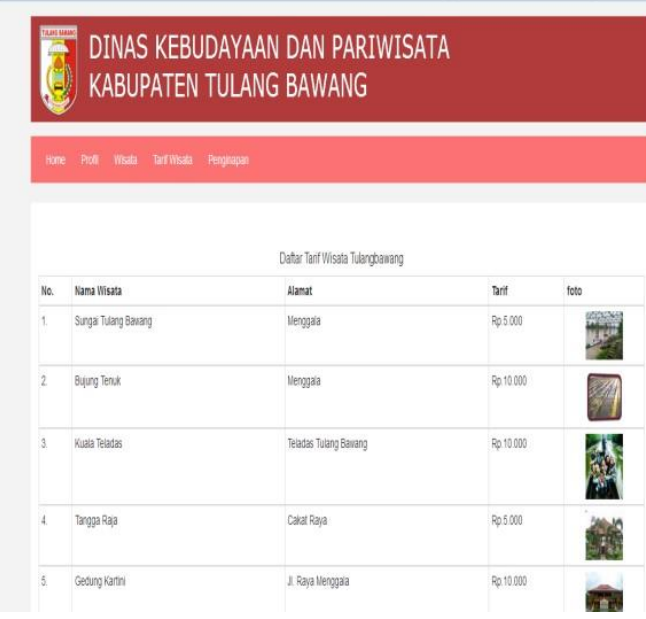

Gambar 4 Tampilan Menu Tarif Wisata

Keterangan : Menu Tarif Wisata Berisi Nama-Nama Wisata, Alamat Tempat Wisata, Dan Foto Wisata.

\section{Tampilan Menu Penginapan}

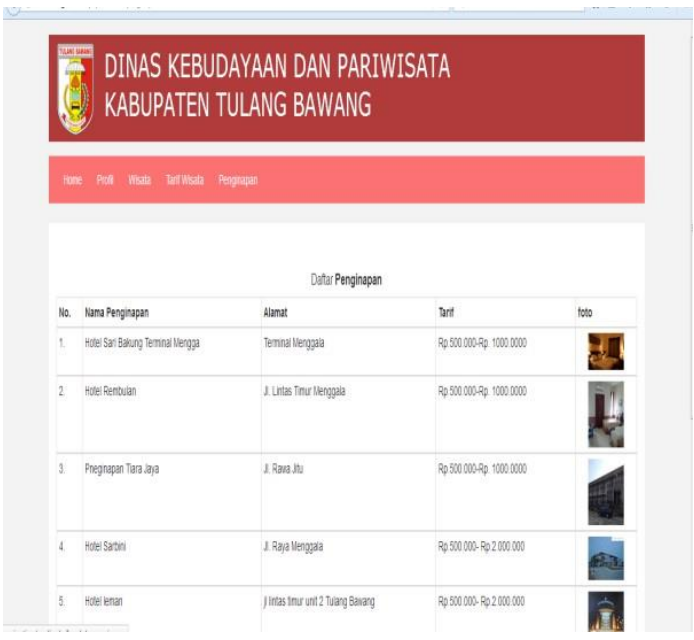

Gambar 5 Tampilan Penginapan

Keterangan : Menu penginapan berisi informasi mengenai penginapan yang ada di Tulang Bawang.

\section{Tampilan Edit Wisata}

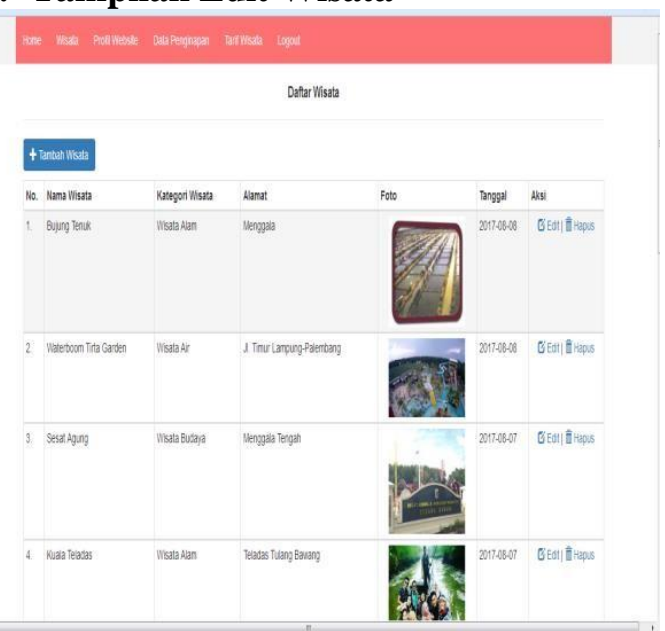

Gambar 6 Tampilan Edit Wisata

Keterangan : Tampilan edit wisata berisi menu tambah wisata jika ada nama wisata yang akan ditambah, dan juga ada menu aksi yang edit dan hapus.

\section{Tampilan Edit Profil Dinas}

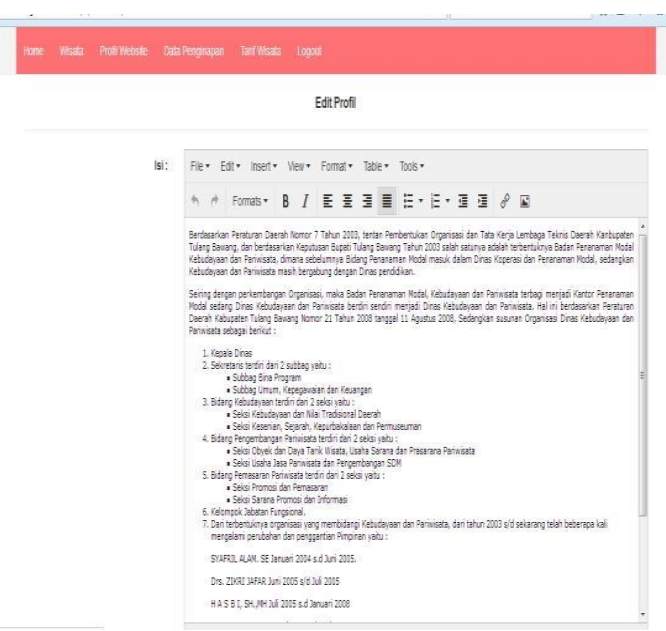

Gambar 7 Tampilan Edit Profil Dinas

Keterangan : Edit Profil Berguna Untuk Mengganti Atau Merubah Profil Dinas 


\section{JURnal InformASI dan KomPUTer \\ Volume 6 Nomor 1 2018}

\section{Tampilan Edit Tarif Wisata}

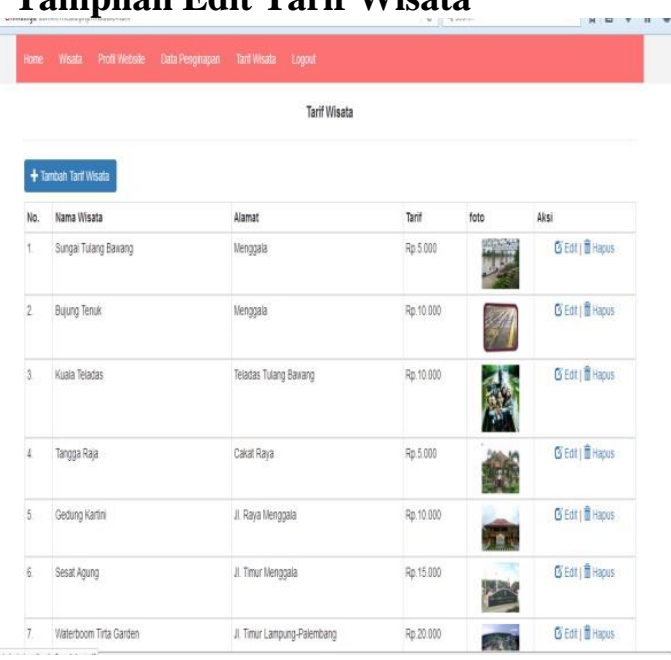

Gambar 8 Tampilan Edit Tarif Wisata

Keterangan : Edit Tarif Wisata Berisi Menu Tambah, Edit Atau Hapus Tarif Wisata jika ada yang mau diganti.

\section{Tampilan Edit Penginapan}

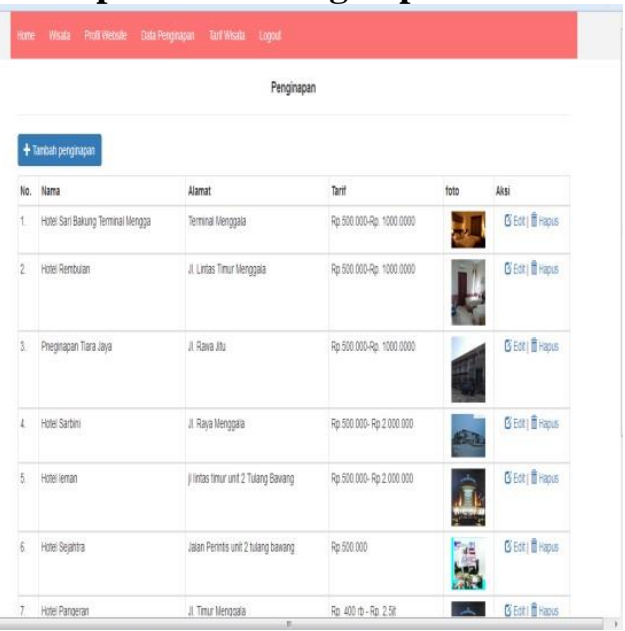

Gambar 9 Tampilan Edit Penginapan

Keterangan : Edit Penginapan Berisi Menu Tambah, Edit, Dan Hapus Penginapan.

\section{Tampilan Cetak Laporan Data Wisata}

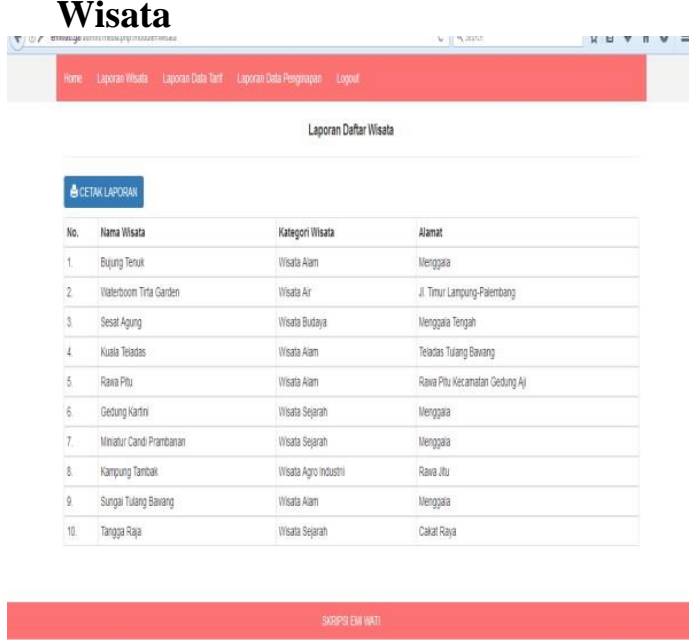

Gambar 10 Tampilan Cetak Laporan Data Wisata

Keterangan : Menu Cetak Laporan Merupakan Menu Kepala Dinas Jika Dia Ingin Mencetak Laporan Data Wisata

\section{Tampilan Cetak Laporan Data Tarif wisata}

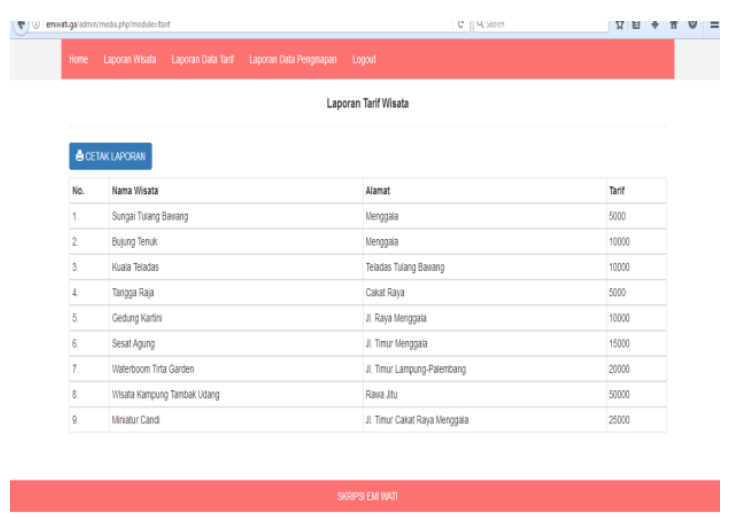

Gambar 11 Tampilan Cetak Laporan Data Tarif Wisata

Keterangan : Menu Cetak Laporan Merupakan Menu Kepala Dinas Jika Dia Ingin Mencetak Laporan Data Tarif Wisata 


\section{Tampilan Cetak Laporan Data Penginapan}

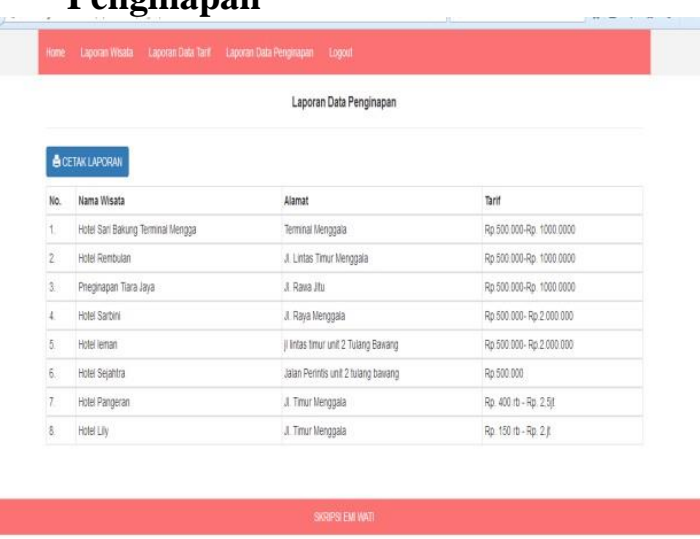

Gambar 12 Tampilan Cetak Laporan Data Penginapan

Keterangan : Menu Cetak Laporan Merupakan Menu Kepala Dinas Jika Dia Ingin Mencetak Laporan Data Penginapan

\section{Tampilan Laporan Data Wisata}

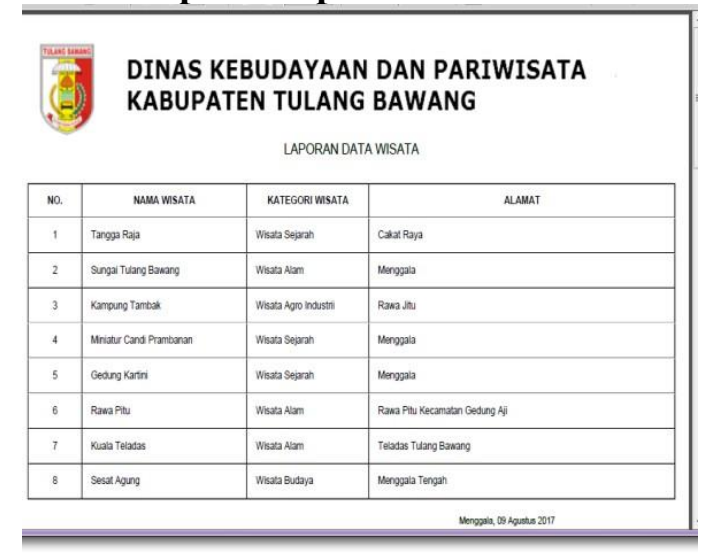

Gambar 13 Tampilan Laporan Data Wisata

\section{Tampilan Laporan Data Tarif} Wisata

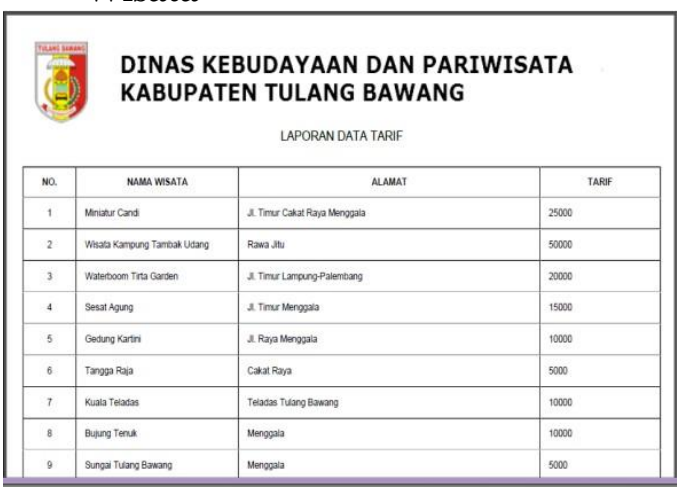

Gambar 14 Tampilan Laporan Data Tarif Wisata

\section{Tampilan Laporan Data Penginapan}

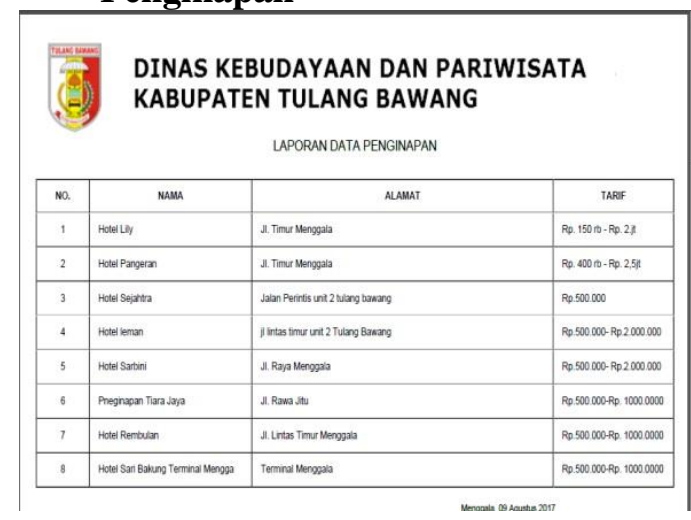

Gambar 4.15 Tampilan Laporan Data Penginapan

\subsection{Keunggulan Sistem}

Keunggulan sistem yang baru bila dibandingkan dengan sistem lama, dapat menjalankan sistem ini dimanapun, kapanpun, tanpa harus melakukan penginstalan, dapat dijalankan disistem operasi manapun, dapat diakses dibanyak media misalnya komputer dan handphone.

\subsection{Kelemahan Sistem}

Sistem ini tidak menutup kemungkinan masih banyak kekurangan 
tentu diantaranya : dibutuhkan koneksi internet yang handal dan stabil agar saat dijalankan bisa berjalan dengan baik dan lancar, dibutuhkan sistem keamanan yang baik dikarenakan dijalankan secara terpusat, sehingga apabila server dipusat down maka sistem tidak bisa berjalan.

\section{KESIMPULAN}

Pariwisata merupakan salah satu sektor yang dapat menghasilkan pendapatan yang luar biasa bagi suatu daerah, terutama apabila dikelola dengan baik. Tetapi pengolahan yang baik tidak akan berjalan tanpa adanya sarana pendukung yang melatar belakangi tujuan tersebut.

Salah satu sarana pendukung yang dimaksud adalah dengan adanya sebuah sistem informasi pariwisata yang diharapkan bisa memenuhi kebutuhan pengguna akan informasi pariwisata yang akan menjadi tujuan wisata, selain itu juga dapat menjadi media promosi bagi suatu daerah tersebut. Dari hasil pembahasan yang telah penulis jelaskan maka penulis mengambil kesimpulan diantaranya :

1. Website ini memberikan kemudahan bagi masyarakat Tulang Bawang khususnya dan masyarakat luar umumnya, untuk mencari informasi mengenai pariwisata dan kebudayaan yang ada dikabupaten Tulang Bawang.

2. Website ini juga sebagai media promosi pariwisata kabupaten Tulang Bawang kepada masyarakat ditanah air bahkan internasional.

\section{SARAN}

Dari kesimpulan diatas, penulis menyarankan beberapa hal sebagai berikut :

1. Pembangunan website ini masih bisa dibuat sebagus dan semenarik mungkin.
2. Website ini dapat dikembangkan lebih lanjut terutama dalam tampilan sistem.

3. Dari segi isinya website ini masih belum sempurna, oleh karena itu ada baiknya ditambah beberapa informasi yang lebih lengkap.

4. Agar pengunjung tidak cepat bosan mungkin bisa menambah animasi, karena dengan animasi website ini juga bisa kelihatan indah.

\section{DAFTAR PUSTAKA}

Abdul Kodir , Pengenalan sistem informasi , Andi Offset, Yogyakarta, 2012.

Al-barha, Analisa dan perancangan sistem informasi, Graha Ilmu, Yogyakarta, 2012

Al-Fatta, Analisis sistem, Andi Offset, Yogyakarta , 2014.

Ari Kunto, Cara Menentukan Sampel, Grasindo, Jakarta, 2011.

Gordon Davis, Informasi, Presindo, Jakarta, 2013.

Halim, F.N. , Sistem Informasi

Pariwisata, Grasindo, Yogyakarta, 2011. Jogianto, Sistem Informasi Sebagai Buatan Manusia, Andi Offset, Yogyakarta, 2011

KBBI, Pariwisata \& Kebudayaan, Gramedia, Jakarta, 2013.

Pressman, Pengertian Metode

Waterfall, Gramedia, Bandung, 2012.

Rosa Salahudin, Alat Pengembangan

Sistem, Andi Offset, Yogyakarta, 2011

Saryono, Penelitian kualitatif,

Grasindo, Jakarta, 2012.

Zakiyudin, Sistem Informasi, Gramedia, Jakarta, 2011.

//www.gunadarma.ac.id/ujicoba dan perawatan sistem// 
JURnal InformASI dan KomPUTer

Volume 6 Nomor 1 2018 
JURnal InformASI dan KomPUTer

Volume 6 Nomor 12018

P-ISSN 2337-8344 